\title{
Prolactin Levels in Workers Exposed to Chemical, Physical and Psycho-Social Urban Stressors
}

\author{
Francesco Tomei, Manuela Ciarrocca, Emilia Cherubini, Maria V. Rosati, Carlo Monti, \\ Assunta CAPOzZella and Gianfranco ToMeI
}

Department of Occupational Medicine, University of Rome "La Sapienza"

\begin{abstract}
Prolactin Levels in Workers Exposed to Chemical, Physical and Psycho-Social Urban Stressors: Francesco Tomel, et al. Department of Occupational Medicine, University of Rome "La Sapienza", Italy-The aim of this study was to evaluate whether traffic police officers exposed to chemical, physical and psycho-social stressors, are at risk for alterations in plasma levels of prolactin (PRL) compared to a control group. Plasma PRL levels were evaluated in 92 male and 51 female, non-smoker, traffic police officers exposed to urban stressors and in 92 male and 51 female controls, matched by sex, age and working life (mean, SD and distribution), after excluding workers with the principal extra-occupational confounding factors. Mean PRL levels were significantly higher than controls in non-smoker, male and female traffic police officers (respectively, $p=0.000$ and $p=0.013$ ). The number of non-smoker, male and female traffic police officers with PRL values outside the upper normal limit for our laboratory was higher than, but not significantly different from controls. Mean PRL levels were not significantly higher than controls in smoker, male and female traffic police officers. The number of smoker, male and female traffic police officers with PRL values outside the normal limit for our laboratory was not significantly different from controls. The results suggest that exposure to urban chemical and physical stressors, interacting with psychosocial factors, may have an influence on PRL levels in traffic police officers. The level of plasma PRL might be a useful early biological marker for workers exposed to urban stressors.
\end{abstract}

(J Occup Health 2006; 48: 253-260)

Key words: Traffic police officers, Prolactin, HPA-axis, Stressor, Urban pollutants

Received Aug 3, 2005; Accepted Apr 18, 2006

Correspondence to: F. Tomei, Department of Occupational Medicine, University of Rome "La Sapienza", Viale Regina Elena 336,00161 Rome, Italy (e-mail: francesco.tomei@uniromal.it)
Prolactin (PRL) is a proteic hormone, synthesised and secreted mainly by the lactogenic cells of the adenohypophysis. This hormone has more than 300 different biological actions on the nervous, endocrine and immune systems ${ }^{1,2)}$.

Several studies in the literature have shown that urban workers, such as traffic police officers, are daily exposed to chemical (air pollutants), physical (e.g., noise) and psycho-social stressors ${ }^{3-9}$. For these workers, the working environments correspond to the life environment of the general population.

The results of our previous studies have indicated that besides the well known effects on the cardiovascular and respiratory systems caused by the exposure to air pollutants ${ }^{10,11)}$, there are also effects on the hypothalamicpituitary-adrenal (HPA) axis and related systems, resulting from chronic exposure to chemical and physical stressors $^{12-18)}$. On the basis of the results of these studies, the tested neuro-hormones, growth hormone $(\mathrm{GH})$, insulinlike growth factor type 1 (IGF-1), adrenocorticotropic hormone (ACTH), 5-hydroxyindoleacetic acid (5-HIAA), cortisol (CORT) and vasopressin (VP) might be useful early biological markers of stress and stress-related factors. Indeed, the changes of these neuro-hormones would be indicative of a HPA system response to chemical and physical urban stressors interacting with and adding to the psycho-social ones ${ }^{12-18)}$.

Studies in the literature have proposed that certain urban chemical stressors may alter plasma levels of prolactin (PRL). These agents are benzene, xylene, styrene, toluene ${ }^{19-25)}$, lead and manganese ${ }^{26-31)}$ ozone $^{32)}$ and other contaminants ${ }^{33)}$. In addition to these, physical stressors such as traffic noise might impair the prolactin plasma levels ${ }^{34-36)}$.

In fact, it is well known that personal exposure to pollutants from direct exposure to traffic fumes, as experienced by some categories of outdoor workers, such as traffic police officers, may be considered higher than personal exposure of indoor workers (particularly in 
Italian cities $)^{37)}$. For this reason, in traffic police, we have already evaluated, in previous researches, the following parameters: urinary S-phenilmercapturic acid, trans-trans muconic acid, pyrenol acid; environmental and blood benzene; sister chromatid exchanges (SCE) and micronuclei (MN) in peripheral blood lymphocytes; and antibodies to the benzo(a)pyrene $(\mathrm{BaP})$ diol exposideDNA adducts in sera. In particular exposure dosages to benzene (time weight average, TWA) (mean 10.7 and $3.6 \mu \mathrm{g} / \mathrm{m}^{3}$, respectively) and toluene (mean 40.7 and 13.5 $\mu \mathrm{g} / \mathrm{m}^{3}$, respectively) were significantly higher among traffic police officers than indoor workers ${ }^{38-41)}$.

Besides the above mentioned urban pollutants, it is known that traffic police officers are exposed to psychosocial stressors. One of our previous researches has ascertained, through the compilation and elaboration of a questionnaire, a greater subjective stress in traffic police officers compared to a control group. Sources of psychosocial stressor for the traffic police officers may be relations with the public, exposure to episodes of criminality, and the need to maintain high levels of services in various contexts ${ }^{6}$.

Although unleaded petrol has been introduced, a mixed regime existed in Italy at the time of this study (use of leaded and unleaded petrol). Moreover, it is probable that anti-knocking additives containing manganese and nickel are present in fuels, and the use of unleaded petrol may be the cause of the increase in benzene in the urban atmosphere.

The aim of this study was to evaluate whether traffic police officers exposed to chemical, physical and psychosocial stressors, are at risk for alterations in plasma levels of PRL compared to a control group.

\section{Materials and Methods}

The research was carried out on a initial sample of 973 Municipal Police employees: 598 traffic police officers and 375 controls.

The traffic police officers exposed to urban pollutants worked on parking control, control of access openings to limited-traffic areas, and control of crossroads or roads with heavy traffic. Subjects with indoor activities such as administrative and bureaucratic duties, with a lower level of exposure, were used as the control group. Traffic police and controls worked $7 \mathrm{~h} / \mathrm{d}$ for at least $5 \mathrm{~d} / \mathrm{wk}$. In the initial sample there were no workers reporting working night or rotating shifts.

For the inclusion into the study a questionnaire with physiological anamnesis (pharmacological therapies, use of paints, pesticides and solvents during time off, smoking habit i.e. number of cigarettes smoked, years of subjection to the habit, drinking habit i.e. number of glasses of wine, beer or spirits drunk per day), remote and near pathological anamnesis and previous and current working history, also including the confounding factors reported below was collected for all workers, in the presence of a physician.

In order to avoid the influence of confounding factors, excluded from the study were any worker who answered affirmatively to items related to the following: drinking habit (number of glasses of wine, beer or spirits drunk per day); previous and/or current gynaecological pathologies (ovarian polycystosis, hyster-adnexectomy, uterine fibromas, uterine myomectomy, fibroadenomas, cysts and nodules of the mammary gland $)^{42)}$; previous and/or current endocrinologic pathologies (thyroid nodules, thyroidectomy, thyroiditis, hyperthyroidism and hypothyroidism pathologies, adenohypophysis pathologies) ${ }^{43)}$; recent use (during the six months preceding the sample), of drugs capable of altering plasma levels of PRL (i.e. methimazole, thyroxin, medicaments with an estrogenic content, bromocriptine, benzodiazepine, oral contraceptives $)^{44,45}$. Subjects reporting exposure to solvents, paints and pesticides during time-off or other previous or current jobs were excluded $^{30)}$. There were no pregnant women or nursing mothers in the initial sample; these are conditions in which PRL is physiologically increased ${ }^{2}$. Women aged over 50 were excluded from the study because the hypoestrogenic state occurring during menopause causes a physiological reduction in plasma levels of PRL ${ }^{46}$.

Thus 230 traffic police officers and 198 controls were excluded from the study.

Workers who reported a smoking habit (158 traffic police officers and 101 controls) were evaluated separately to verify the hormonal effects of tobacco smoke on PRL levels of workers of both sexes ${ }^{47)}$.

In the non-smoker group, traffic police officers were matched for sex, age and working life (mean, SD and distribution), with controls. Two hundred and eigthy six subjects were included in the non-smoker group: 143 traffic police officers ( 92 men and 51 women, Tables 1 and 2) and 143 controls (92 men and 51 women, Tables 1 and 2).

The breakdown of the workers by sex was necessary in view of the greater sensitivity to both physiological and pathological stimuli of the response of PRL in women, compared to men ${ }^{48)}$.

In the smoker group, traffic police officers were matched for sex, age and working life (mean, SD and distribution) with controls. One hundred sixteen subjects were included in the smoker group: 58 traffic police officers (37 men and 21 women, Table 1 and Table 2) and 58 controls ( 37 men and 21 women, Table 1 and Table 2).

Also, non-smoker, male and female traffic police officers were matched for sex, age and working life (mean, SD and distribution) with smoker, male and female controls, respectively (Table 1 and Table 2).

All the subjects agreed to the processing of their 
Table 1. Mean age, mean working life, mean PRL values and number of subjects with PRL values outside the normal limit for our laboratory in male, non-smoker and smoker, traffic police officers and controls

\begin{tabular}{|c|c|c|c|c|}
\hline & \multicolumn{2}{|c|}{$\begin{array}{c}\text { Male, non-smoker } \\
\qquad \mathrm{N}=184\end{array}$} & \multicolumn{2}{|c|}{$\begin{array}{l}\text { Male, smoker } \\
\qquad N=74\end{array}$} \\
\hline & $\begin{array}{l}\text { Police officers } \\
\qquad N=92\end{array}$ & $\begin{array}{c}\text { Controls } \\
\mathrm{N}=92\end{array}$ & $\begin{array}{l}\text { Police officers } \\
\qquad N=37\end{array}$ & $\begin{array}{c}\text { Controls } \\
\mathrm{N}=37\end{array}$ \\
\hline \multicolumn{5}{|l|}{ Age } \\
\hline Mean \pm SD & $47.0 \pm 6.9$ & $47.0 \pm 7.0$ & $47.2 \pm 6.7$ & $47.5 \pm 5.8$ \\
\hline $\min -\max$ & $33-60$ & $33-60$ & $33-60$ & $33-60$ \\
\hline \multicolumn{5}{|l|}{ Working life } \\
\hline Mean \pm SD & $9.2 \pm 3.5$ & $8.6 \pm 4.9$ & $9.7 \pm 5.8$ & $9.1 \pm 5.6$ \\
\hline $\min -\max$ & $2-24$ & $2-24$ & $2-25$ & $2-25$ \\
\hline \multicolumn{5}{|l|}{ PRL values } \\
\hline Mean \pm SD & $10.1 \pm 7.1^{*} \S$ & $6.9 \pm 3.5$ & $7.6 \pm 2.1^{\#}$ & $7.4 \pm 3.6$ \\
\hline $\min -\max$ & $3-38$ & $3-25$ & $4-12$ & $4-21$ \\
\hline $\mathrm{PRL}<5 \mathrm{ng} / \mathrm{ml}$ & $8 \quad(8.7 \%)^{\#}$ & $15(16.3 \%)$ & $1 \quad(2.7 \%)^{\#}$ & $6(16.2 \%)$ \\
\hline $\mathrm{PRL} \geq 5 \leq 15 \mathrm{ng} / \mathrm{ml}$ & $73(79.3 \%)^{\#}$ & $74(80.4 \%)$ & $36(97.3 \%)^{\#}$ & $30(81.1 \%)$ \\
\hline $\mathrm{PRL}>16$ ng/ml & $11(11.9 \%)^{\# \S \S}$ & $3 \quad(3.3 \%)$ & 0 & $1(2.7 \%)$ \\
\hline
\end{tabular}

${ }^{*} p=0.000$ with respect to controls, ${ }^{*} p=$ not significant with respect to controls, ${ }^{\S} p=0.038$ with respect to smoker traffic police officers, ${ }^{\S} p=0.033$ with respect to smoker traffic police officers.

Table 2. Mean age, mean working life, mean PRL values and number of subjects with PRL values outside the normal limit for our laboratory in female, non-smoker and smoker, traffic police officers and controls

\begin{tabular}{lcccc}
\hline & \multicolumn{2}{c}{ Female, non smoker $\mathrm{N}=102$} & \multicolumn{2}{c}{ Female, smoker } \\
& Police officers & Controls & Police officers & Controls \\
& $\mathrm{N}=51$ & $\mathrm{~N}=51$ & $\mathrm{~N}=21$ & $\mathrm{~N}=21$ \\
\hline Age & & & & \\
Mean \pm SD & $39.8 \pm 4.3$ & $40.2 \pm 4.2$ & $41.2 \pm 4.2$ & $41.3 \pm 4.5$ \\
min-max & $33-50$ & $33-50$ & $36-50$ & $33-50$ \\
Working life & & & & \\
Mean \pm SD & $9.2 \pm 3.5$ & $8.4 \pm 3.5$ & $8.1 \pm 3.1$ & $7.8 \pm 3$ \\
min-max & $2-17$ & $2-17$ & $2-11$ & $3-12$ \\
PRL values & & & & \\
Mean \pm SD & $18.1 \pm 14.0 * \S$ & $12.4 \pm 7.4$ & $11.3 \pm 4.5^{\#}$ & $11 \pm 4.5$ \\
min-max & $6-86$ & $4-46$ & $5-23$ & $5-25$ \\
PRL $<5 \mathrm{ng} / \mathrm{ml}$ & 0 & $1(2 \%)$ & 0 & 0 \\
PRL $\geq 5 \leq 25 \mathrm{ng} / \mathrm{ml}$ & $43(84.3 \%)^{\#}$ & $48(94.1 \%)$ & $21(100 \%)^{\#}$ & $21(100 \%)$ \\
PRL $>26 \mathrm{ng} / \mathrm{ml}$ & $8(15.7 \%)^{\#}$ & $2(3.9 \%)$ & 0 & 0 \\
\hline
\end{tabular}

${ }^{*} p=0.013$ with respect to controls, ${ }^{*} p=$ not significant with respect to controls, ${ }^{\S} p=0.033$ with respect to smoker traffic police officers.

personal data, declared that they were aware that the data came within the category of "sensitive data", and agreed for the data arising from the study to be processed anonymously and collectively, with methods and scientific purposes in accordance with the principles of the Helsinki Declaration.

All the workers included in the study gave venous blood samples which were assayed by RIA for PRL. The 
normal ranges of this assay used in our laboratory are 5$15 \mathrm{ng} / \mathrm{ml}$ for men and 5-25 $\mathrm{ng} / \mathrm{ml}$ for women.

A 10-ml sample of venous blood was taken from each worker, between 8 and 10 a.m., after overnight fasting. Samples were kept at the workplace in a refrigerator at $-4{ }^{\circ} \mathrm{C}$ until they were moved to the laboratory (by refrigerator), where they were immediately centrifuged to obtain serum, which was kept at $-20^{\circ} \mathrm{C}$ until it was analysed (within $3 \mathrm{~d}$ ).

The laboratory did not know which patients were included in the trial, although physicians and technicians knew a study was in progress.

For the methodological organization of data collection and for the preparation of the clinical anamnestic questionnaire, specific socio-communicative competences related to the development of tools suitable for the collection of information and analysis data were used.

\section{Statistical Analysis}

Statistical analysis of the data was based on the calculation of the mean, standard deviation, distribution, range and frequency according to the nature of the single variables.

The differences between the means were compared using Student's t test for the unpaired data. The frequencies of the single variables were compared using the chi-square test with Yates' correction setting up a fourway contingency table and Fisher's exact test setting up a four-way contingency table. Fisher's exact test was used when the total was less than 40 and the smallest of the four expected values was less than 5 .

The differences were considered significant when the $p$ values were $\leq 0.05$.

The statistical analysis was done using the statistical program Solo-BMDP ${ }^{\mathrm{TM}}$ Statistical Software.

\section{Results}

In the non-smoker group mean PRL levels were significantly higher than controls in male traffic police officers $(p=0.000)$ (Table 1$)$. In the non-smoker group mean PRL levels were significantly higher than controls in female traffic police officers $(p=0.013)$ (Table 2).

The number of male traffic police officers with PRL values outside the upper normal limit for our laboratory was higher than, but not significantly different from controls ( $p=$ n.s.) (Table 1).

The number of female traffic police officers with PRL values outside the upper normal limit for our laboratory was higher than, but not significantly different from controls ( $p=$ n.s.) (Table 2).

The resulting ratio of the average PRL values between non-smoking, male and female workers was 1: 1.8 .

In the smoker group there were no significant differences in mean PRL values in male (Table 1) and female (Table 2) traffic police officers compared to controls. Similarly no significant differences were found in the numbers of male and female traffic police officers with PRL values outside the normal limit for our laboratory compared to controls (Tables 1 and 2).

The mean PRL value in male, non-smoker traffic police officers was significantly higher than male, smoker traffic police officers $(p=0.038)$ (Table 1).

The mean PRL values in female, non-smoker traffic police officers was significantly higher than female, smoker traffic police officers $(p=0.033)$ (Table 2).

The number of male, non-smoker traffic police officers with PRL values outside the upper normal limit for our laboratory was significantly higher than male, smoker traffic police officers $(p=0.033)$ (Table 1$)$.

The number of female, non-smoker traffic police officers with PRL values outside the upper normal limit for our laboratory was higher than, but not significantly different from female, smoker traffic police officers ( $p=$ n.s.) (Table 2).

\section{Discussion}

Considering that the principal confounding factors were excluded, and that the subjects investigated were matched by sex, age and working life, the data suggest the possibility that exposure to chemical urban pollutants ${ }^{21,24,26,27,30)}$, in particular, can alter plasma PRL levels, in addition to traditional psychosocial stressors.

The City Police operators studied were exposed, for 7 $\mathrm{h}$ a day for $5 \mathrm{~d}$ a week, to different stressors compared to the subjects who worked indoors. In particular, as far as chemical agents are concerned, in our previous studies we found levels of exposure to benzene (mean $7 \mathrm{~h}$ ), a little less than $10 \mathrm{mg} / \mathrm{m}^{3}$ in traffic police officers and about three times lower in controls ${ }^{38,39}$. In this study we didn't measure directly chemical and physical pollutants affecting the population study; therefore the results should be interpreted with the caution and conservatively. However, it can be assumed that chemical and physical stressors had an effect on the HPA-axis, and therefore on secretion of PRL, in the asymptomatic traffic police officers studied, and that they interacted with psychosocial ones $^{49)}$.

The results obtained suggest the following considerations:

1. The fact that there was a significant difference between mean plasma PRL values of non-smoker traffic police officers and controls of both sexes suggests that this difference may be of some clinical relevance even when the mean is "numerically normal".

2. The fact that the number of non-smoker, male and female, traffic police officers with PRL values outside the upper normal limit for our laboratory was higher than, but not significantly different from controls, suggests that those modifications should be considered valid even if 
the deviation is not as wide as is often found in medical pathology (as microprolactinomas).

Accordingly, PRL might be used in occupational settings as an early biological marker valuable for the group, even before the onset of diseases.

Our results confirmed that the smoking habit can alter plasma concentrations of PRL. The finding of our study that PRL levels were significantly lower among smoker traffic police officers of both sexes might be correlated to the action on PRL secretion of some substances in smoke. Animal and human studies, have shown the effect of tobacco smoke on PRL secretion in both sexes ${ }^{47)}$. Nicotine and other substances contained in smoke can cause inhibition of PRL secretion, probably through action on the tubero-infundibular dopaminergic neurons, inducing an increase in the secretion of dopamine ${ }^{50,51)}$. Our results confirmed that this inhibition annuls differences between PRL values in smoker traffic police officers and in controls of both sexes.

In contrast to what is seen with all the other pituitary hormones, PRL secretion is tonically suppressed by the hypothalamus; PRL is secreted only when this inhibition is released. Dopamine is the major PRL-inhibiting factor. It is secreted into portal blood by hypothalamic neurons and binds with the receptors on lactotroph cells, exerting its inhibition on both the synthesis and secretion of PRL. Agents and drugs that interfere with dopamine secretion or receptor binding lead to enhanced secretion of PRL. PRL secretion is regulated by other mechanisms in addition to tonic inhibition by dopamine. Several hormones positively regulate PRL secretion, including thyroid-releasing hormone, gonadotropin-releasing hormone, vasoactive intestinal polypeptide, and estrogens exert a positive control over PRL synthesis and secretion $^{52)}$.

The mechanisms giving rise to a change of PRL levels are complex and not fully elucidated. An increase in plasma PRL following occupational exposure to urban pollutants might be due to dopaminergic depletion of the hypothalamic neuron structures (TIDA: tuberoinfundibular dopaminergic neuron population $)^{53-57)}$. Pollutants might therefore act as stressors on the HPAaxis with TIDA as its target. According to the literature, the increase in PRL concentrations observed in our study might have been derived mainly from an indirect "dopamine-depletion" mechanism. Assuming this was true, pollutants might play a role even in psychiatric pathologies where there is also depletion of the hypothalamic dopamine (as in mood disturbances) ${ }^{58-68)}$.

The ratio of about 1:1.8 between the PRL values of male and female non-smokers might indicate a different role for PRL in women, from that in $\mathrm{men}^{48)}$. On this subject some authors have speculated that different role might contribute to the greater prevalence of certain types of mood disturbance in females ${ }^{48,69)}$.
The neuro-endocrine system of traffic police officers is exposed to the action of many occupational stressors, among which traffic noise plays an important role. Our recent study showed an increase in PRL after acute exposure to noise ${ }^{34)}$. Recently, it has been shown with rats that subchronic noise exposure was able to induce a significant increase in PRL levels and marked changes in the physiological response to a novel acute stressor (ozone), indicating a changed physiological status ${ }^{35}$. Reports in the literature about chronic exposure to noise are conflicting. It might therefore be supposed that the combination of chronic exposure to air pollutants and noise can cause an increase in plasmatic PRL values ${ }^{36)}$.

It is possible that urban pollution can interact with psychosocial stressors and that chemical, physical and psychosocial agents can alter the neuroendocrine system.

Reports in the literature point out that the PRLsecretory response differs depending on the nature of stress leading to a difficulty in defining a univocal model of action for the different environmental stressors ${ }^{2}$.

In conclusion, it is possible that an increase in plasma PRL concentration could be a useful early biological marker of exposure to urban stressors, usable in an occupational setting. Such changes might be regarded as early biological markers of risk for the general population exposed to environmental stressors, too, even if the ways and times are different from those of working populations, such as traffic police officers.

\section{References}

1) LA Villanueva and E Garcia Lara: Prolactin and its role in the regulation of ovarian function. Ginecol Obstet Mex 66, 512-516 (1998)

2) ME Freeman, B Kanyicska, A Lerant and G Nagy: Prolactin: structure, function, and regulation of secretion. Physiol Rev 80, 1523-1631 (2000)

3) DL Ely and RA Mostardi: The effect of recent life events stress, life assets, and temperament pattern on cardiovascular risk factors for Akron City police officers. J Human Stress 12, 77-91 (1986)

4) J Szaniszlo and G Ungvary: Polycyclic aromatic hydrocarbon exposure and burden of outdoor workers in Budapest. J Toxicol Environ Health A 62, 297-306 (2001)

5) RR Gershon, S Lin and X Li: Work stress in aging police officers. J Occup Environ Med 44, 160-167 (2002)

6) P Pancheri, A Martini, L Tarsitani, MV Rosati, M Biondi and F Tomei: Assessment of subjective stress in the municipal police force of the city of Rome. Stress and Health 18, 125-132 (2002)

7) PA Collins and AC Gibbs: Stress in police officers: a study of the origins, prevalence and severity of stressrelated symptoms within a county police force. Occup Med (Lond) 53, 256-264 (2003)

8) R Bono, E Scursatone, T Schiliro and G Gilli: Ambient air levels and occupational exposure to benzene, 
toluene, and xylene in northwestern Italy. $\mathrm{J}$ Toxicol Environ Health A 66, 519-531 (2003)

9) V Wiwanitkit, J Suwansaksri and S Soogarun: A note on urine trans, trans muconic acid level among a sample of Thai police: implication for an occupational health issue. Yale J Biol Med 76, 103-108 (2003)

10) P Volpino, F Tomei, C La Valle, E Tomao, MV Rosati, M Ciarrocca, S De Sio, B Cangemi, R Vigliarolo and F Fedele: Respiratory and cardiovascular function at rest and during exercise testing in a healthy working population: effects of outdoor traffic air pollution. Occup Med 54, 475-482 (2004)

11) F Tomei, MV Rosati, TP Baccolo, E Cherubini, M Ciarrocca, T Caciari and E Tomao: Ambulatory (24 hours) blood pressure monitoring in police officers. $\mathbf{J}$ Occup Health 46, 235-243 (2004)

12) F Tomei, MV Rosati, TP Baccolo, A Bernardini, M Ciarrocca and E Tomao: Plasma concentration of adrenocorticotropic hormone in traffic policemen. $\mathrm{J}$ Occup Health 45, 242-247 (2003)

13) F Tomei, MV Rosati, TP Baccolo, A Morelli, V Anzelmo, M Ciarrocca and E Tomao: Occupational exposure to urban pollutants and plasma growth hormone (GH). J Environ Sci Health Part A 38, 10171024 (2003)

14) F Tomei, MV Rosati, M Ciarrocca, TP Baccolo, M Gaballo, T Caciari and E Tomao: Plasma cortisol levels and workers exposed to urban pollutants. Ind Health 41, 320-326 (2003)

15) F Tomei, MV Rosati, M Ciarrocca, E Cherubini, TP Baccolo, V Anzelmo, E Tomao: Work exposure to urban pollutants and urinary homovanillic acid. J Environ Sci Health (Part A) 38, 2909-2918 (2003)

16) F Tomei, M Ciarrocca, MV Rosati, TP Baccolo, P Fiore, P Perrone and E Tomao: Occupational exposure to urban pollutants and plasma insulin-like growth factor 1 (IGF-1). Int J Environ Health Res 14,135-142 (2004)

17) F Tomei, M Ciarrocca, MV Rosati, TP Baccolo, F Grimaldi and E Tomao: Exposure to urban pollutants and plasma vasopressin in traffic policemen. Ind Health 42, 246-251 (2004)

18) F Tomei, MV Rosati, TP Baccolo, M Ciarrocca, T Caciari and E Tomao: Occupational exposure to urban pollutants and urinary 5-hydroxy-3-indoleacetic acid. J Environ Health 66, 38-42 (2004)

19) A Mutti, PP Vescovi, M Falzoi, G Arfini, G Valenti and I Franchini: Neuroendocrine effects of styrene on occupationally exposed-workers. Scand J Work Env Health 10, 225-228 (1984)

20) A Mutti, M Falzoi, A Romanelli, MC Bocchi, C ferrosi and I Franchini: Brain dopamine as a target for solvent toxicity: effect of some monocyclic aromatic hydrocarbons. Toxicology 49, 77-82 (1988)

21) GC Hsieh, RP Sharma and RD Parker: Hypothalamicpituitary-adrenocortical axis activity and immune function after oral exposure to benzene and toluene. Immunopharmacology 21, 23-31 (1991)

22) BG Svensson, G Nise, EM Erfurth, A Nilsson and S Skerfving: Hormone status in occupational toluene exposure. Am J Ind Med 22, 99-107 (1992)
23) G von Euler, SO Ogren, P Eneroth, K Fuxe and JA Gustafsson: Persistent effects of $80 \mathrm{ppm}$ toluene on dopamine-regulated locomotor activity and prolactin secretion in the male rat. Neurotoxicology 15, 621624 (1994)

24) E Bergamaschi, A Smargiassi, A Mutti, S Cavazzini, MV Vettori, R Alinovi, I Franchini and D Mergler: Pheripheral markers of catecholaminergic dysfunction and symptoms of neurotoxicity among styrene-exposed workers. Int Arch Occup Environ Health 69, 209-214 (1997)

25) HR Lam, O Ladefoged, G Ostergaard, U Hass, SP Lund and L Simonsen: Four weeks'inhalation exposure of Long Evans rats to 4-tert-butyl toluene: effect on evoked potentials, behaviour, and brain neurochemistry. Pharmacol Toxicol 87, 11-17 (2000)

26) AV Chandra, MM Ali, DK Safena and RC Murthy: Behavioral and neurochemical changes in rats simultaneously exposed to manganese and lead. Arch Toxicol 49, 49-56 (1981)

27) S Govoni, F Battaini, C Fernicola, L Castelletti and M Trabucchi: Plasma prolactin concentrations in lead exposed workers. J Environ Pathol Toxicol Oncol 7, 13-15 (1987)

28) A Mutti, E Bergamaschi, R Alinovi, R Lucchini, MV Vettori and I Franchini: Serum prolactin in subjects occupationally exposed to manganese. Ann Clin Lab Sci 26,10-17 (1996)

29) A Smargiassi and A Mutti: Peripheral biomarkers and exposure to manganese. Neurotoxicology 20, 401-406 (1999)

30) A Baccarelli: Occupational agents and endocrine functions: an update of the experimental and human data. Med Lav 90, 650-670 (1999)

31) R Lucchini, E Albini, I Cortesi, D Placidi, E Bergamaschi, F Traversa and L Alessio: Assessment of neurobehavioral performance as a function of current and cumulative occupational lead exposure. Neurotoxicology 21, 805-811 (2000)

32) GK Clemons and JF Garcia: Endocrine aspects of ozone exposure in rats. Arch Toxicol Suppl 4, 301$304(1980)$

33) R Steinmetz, NG Brown, DL Allen, RM Bigsby and N Ben-Jonathan: The environmental estrogen bisphenol A stimulates prolactin release in vitro and in vivo. Endocrinology 138, 1780-1786 (1997)

34) F Tomei, MG Ruffino, E Tomao, TP Baccolo, MV Rosati and F Strollo: Acute experimental exposure to noise and hormonal modifications. J Environ Sci Health A 35, 537-555 (2000)

35) MT van Raaij, CJ Dobbe, B Elvers, A Timmerman, E Schenk, M Oortigiesen and WM Wiegant: Hormonal status and the neuroendocrine response to a novel heterotypic stressor involving subchronic noise exposure. Neuroendocrinology 65, 200-209 (1997)

36) B Fruhstorfer, MG Pritsch, P Ott and G Sturm: Effects of daytime noise load on the sleep-wake cycle and endocrine patterns in man: II. 24 hours secretion of anterior and posterior pituitary hormones and of cortisol. Int J Neurosci 39, 211-221 (1988) 
37) S Fustinoni, M Buratti, R Giampiccolo and A Colombi: Biological and environmental monitoring of exposure to airbone benzene and other aromatic hydrocarbons in Milan traffic wardens. Toxicol Lett 77, 387-392 (1995)

38) F Tomei, S Ghittori, M Imbriani, S Pavanello, A Carere, F Marcon, A Martini, TP Baccolo, E Tomao, A Zijno and R Crebelli: Environmental and biological monitoring of traffic wardens from the city of Rome. Occup Med (Lond) 5, 198-203 (2001)

39) R Crebelli, F Tomei, A Zijno, S Ghittori, M Imbriani, D Gamberale, A Martini and A Carere: Exposure to benzene in urban workers: environmental and biological monitoring of traffic police in Rome. Occup Environ Med 58,165-171 (2001)

40) A Verdina, R Galati, G Falasca, S Ghittori, M Imbriani, F Tomei, L Marcellini, A Zijno, V Del Vecchio and Crebelli R: Metabolic polymorphisms and urinary biomarkers in subjects with low benzene exposure. $\mathrm{J}$ Toxicol Environ Health A 64, 607-618 (2001)

41) R Galati, A Zijno, R Crebelli, G Falasca, F Tomei, F Iecher, P Carta and A Verdina: Detection of antibodies to the Benzo(a)pyrene diol epoxide-DNA adducts in sera from individuals exposed to low doses of polycyclic aromatic hydrocarbons. J Exp Clin Cancer Res 20, 359-364 (2001)

42) N Bracero and HA Zacur: Polycystic ovary syndrome and hyperprolactinemia. Obstet Gynecol Clin North Am 28, 77-84 (2001)

43) AA Luciano: Clinical presentation of hyperprolactinemia. J Reprod Med 44, 1085-1090 (1999)

44) JH Mattox, MT Buckman, J Bernstein, D Pathak and R Kellner: Dopamine agonist for reducing depression associated with hyperprolactinemia. J Reprod Med 31, 694-698 (1986)

45) E Alvarez-Tutor, L Forga-LLenas, R RodriguezErdozain, MJ Goni-Iriarte, E Mendendez Torre and J Alvarez-Tutor: Persistent increase of PRL after oral contraceptive treatment. alteration in dopaminergic regulation as possible etiology. Arch Gynecol Obstet 263, 45-50 (1999)

46) S Karunakaran, RC Page and JA Wass: The effect of the menopause on prolactin levels in patients with hyperprolactinemia. Clin Endocrin (Oxf) 54, 295-300 (2001)

47) LH Amir: Maternal smoking and reduced duration of breastfeeding: a review of possible mechanisms. Early Hum Dev 64, 45-67 (2001)

48) Y Ramot, MJ Rapoport, P Hagag and AJ Wysenbeek: A study of the clinical differences between women and men with hyperprolactinemia. Gynecol Endocrinol 10, 397-400 (1996)

49) M Biondi and A Picardi: Psychological stress and neuroendocrine function in humans: the last two decades of research. Psychother Psychosom 68, 114150 (1999)

50) K Andersson, K Fuxe, P Eneroth, F Mascagni and LF Agnati: Effects of acute intermittent exposure to cigarette smoke on catecholamine levels and turnover in various types of hypothalamic DA and NA nerve terminal systems as well as on the secretion of adenohypophyseal hormones and corticosterone. Acta Physiol Scand 124, 277-285 (1985)

51) K Fuxe, K Andersson, $P$ Eneroth, A Harfstrand and LF Agnati: Neuroendocrine actions of nicotine and of exposure to cigarette smoke: medical implications. Psychoneuroendocrinology 14,19-41 (1989)

52) JE Demaria, GM Nagy, AA Lerant, MI Fekete, CW Levenson and ME Freeman: Dopamine transporters partecipate in physiological regulation of prolactin. Endocrinology 141, 366-374 (2000)

53) WE De Wolf Jr, SA Carr, A Varricchio, PJ Goodhart, MA Mentzer, GD Roberts, C Southan, RE Dolle and LI Kruse: Inactivation of dopamine beta-hydroxylase by p-Cresol: isolation and characterization of covalenty modified active site peptides. Biochemistry 27, 9093 9101 (1988)

54) A Mutti and A Smargiassi: Selective vulnerability of dopaminergic systems to industrial chemicals: risk assessment of related neuroendocrine changes. Toxicol Ind Health 14, 311-323 (1998)

55) M Kanada, M Miyagawa, M Sato, H Hasegawa and $T$ Honma: Neurochemical profile of effects of 28 neurotoxic chemicals on the central nervous system in rats (1). Effects of oral administration on brain contents of biogenic amines and metabolites. Ind Health 32, 145-164 (1994)

56) G von Euler, K Fuxe, T Hansson, SO Ogren, LF Agnati, P Eneroth, A Harfstrand and JA Guastafsson: Effects of chronic toluene exposure on central monoamine and peptide receptor and their interactions in the adult male rat. Toxicology 52,103-126 (1988)

57) A Smargiassi, A Mutti, E Bergamaschi, S Belanger, G Truchon and D Mergler: Pilot study of peripheral markers of catecholaminergic systems among workers occupationally exposed to toluene. Neurotoxicology 17, 769-775 (1996)

58) J Mendlewicz, E Van Cauter, P Linkowski, M L'Hermite and C Robin: Current concepts: I. The 24hour profile of prolactin in depression. Life Sci 27, 2015-2024 (1980)

59) MC Mokrani, F Duval, MA Crocq, P Bailey and JP Macher: HPA axis dysfunction in depression: correlation with monoamine system abnormalities. Psychoneuroendocrinology 22, 63-68 (1997)

60) J Landowski and W Lysiak-Szydlowska: Low serum dopamine beta-hydroxylase activity in patients with panic disorder. Psychiatr Pol 32, 781-788 (1998)

61) L Nicholas, K Dawkins and RN Golden: Psychoneuroendocrinology of depression. Prolactin. Psychiatr Clin North Am 21, 341-358 (1998)

62) DG Dikeos, GN Papadimitriou, D Avramopoulos, G Karadima, EG Daskalopoulou, D Sourey, J Mendlewicz, D Vassilopoulus and CN Stefanis: Association between the dopamine D3 receptor gene locus (DRD3) and unipolar affective disorders. Psychiatr Genet 9, 189-195 (1999)

63) E Haffen and D Sechter: The neurobiology of depression. Rev Prat 49, 707-712 (1999) 
64) J Webster: Dopamine agonist therapy in hyperprolactinemia. J Reprod Med 44, 1105-1110 (1999)

65) G Lambert, M Johansson, H Agren and P Friberg: Reduced brain norepinephrine and dopamine release in treatment-refractory depressive illness: evidence in support of the catecholamine hypothesis of mood disorders. Arch Gen Psychiatry 57, 788-793 (2000)

66) MC Oliveira, CB Pizzarro, L Golbert and C Micheletto: Hyperprolactinemia and psychological disturbance.
Arq Neuropsiquiatr 58, 671-676 (2000)

67) PL Delgado: Depression: the case for a monoamine deficiency. J Clin Psychiatry 61, 7-11 (2000)

68) W Pitchot, J Reggers, E Pinto, M Hansenne, S Fuchs, S Pirard and M Ansseau: Reduced dopaminergic activity in depressed suicides. Psychoneuroendocrinology 26, 331-335 (2001)

69) R Kellner, MT Buckman, GA Fava and D Pathak: Hyperprolactinemia, distress and hostility. Am J Psychiatry 141, 759-763 (1984) 